\title{
The Impact of Exercise on Short-term Memory Fading of Cardiac Rehabilitation Patients in Rural Eastern Kentucky
}

\section{Mark Deaton*}

Department of Health, Wellness and Human Performance, Morehead State University, USA

\begin{abstract}
About $60 \%$ of cardiac patients experience some cognitive impairment and may develop negative cognitive functioning after revascularization procedures. Cognitive impairment can be a major impediment of teaching cardiac patients lifestyle behavior changes, such as the importance of starting an exercise program. Impaired short-term memory could limit understanding of the facts, or their immediate importance. However, there is evidence that exercise may improve short-term memory. Thus, the purpose of this study was to determine the impact of exercise on the acute fading effect of short-term memory for cardiac patients. The conceptual framework is supported by human information processing theories and the Brown Peterson paradigm. This quantitative, quasi-experimental study tested cardiac patients' short-term memory fading, using a short-term memory test, pre and post 60 minutes of exercise. A repeated measures ANOVA was used to analyze the mean scores for each memory test. The target population was from a rural southeastern US State, where one sample of 40 cardiac patients that experienced revascularization procedures was studied. An immediate increase in scores was observed after exercise, which persisted for 15 minutes, and then began to fade. Thus, an ideal window of delivery of cardiac patient educational information was identified immediately, following exercise. A fading of scores was identified throughout the duration of the study, which means participant effort level decreased with continued testing. The positive social change implications include understanding the optimal delivery timing of educational counseling for cardiac patients, in a clinical setting that can result in improvements in short-term memory.
\end{abstract}

\section{Structured Abstract}

Purpose: The purpose of this study was to determine the impact of exercise on the acute fading effect of short-term memory for cardiac patients.

Methods: This quantitative, quasi-experimental study tested cardiac patients' short-term memory fading, using a short-term memory test, pre and post 60 minutes of exercise. A repeated measures ANOVA was used to analyze the mean scores for each memory test.

Results: An immediate increase in scores was observed after exercise, which persisted for 15 minutes, and then began to fade. The interaction of time and day was used to best analyze effects and report results. The time effect (relationship of exercise on short-term memory over time) is reported using Wilks' Lambda results from the multivariate tests. Wilks's $\Lambda=.19, F(3,38)=55.52, p<.001$, multivariate $\eta^{2}=.81$. The day effect results are Wilks's $\Lambda=.88$, $F(2,39)=2.71, p=.081$, multivariate $\eta^{2}=.12$. Thus, an ideal window of delivery of cardiac patient educational information was identified immediately, following exercise.

Conclusions: The positive social change implications include understanding the optimal delivery timing of educational counseling for cardiac patients, in a clinical setting that can result in improvements in short-term memory.

\section{Introduction}

According to Browne et al. [1], nearly $60 \%$ of cardiac patients experience some cognitive impairment after revascularization procedures, and may develop negative cognitive functioning. Thus, this could lead to a patient misunderstanding the educational material taught during a cardiac rehabilitation visit, as ordered by his or her physician. Clinicians teach patients about their condition(s), potential conditions, and general health, to help them understand how to take better care of their health. This health education or health promotion is provided to patients in a hospital, physician's office, or other allied health-affiliated settings by health care professionals. The delivery of this type of education must be precise and consistent, because there is a direct link between receiving patient education and the patient's health [2-4]. Short-term memory plays a vital role in the processing of information to long-term memory $[5,6]$. There is ample evidence that exercise may improve short-term memory [4,7-11].

The purpose of this quantitative, quasi-experimental study was to determine the impact of exercise on the acute fading effect of shortterm memory for cardiac patients at a rural Kentucky hospital. A fading effect between trials and over days was analyzed. The time and day (relationship of exercise on short-term memory immediate, fifteen minutes, and thirty minutes post activity, and the relationship over three days) interaction was addressed with each research question. The results lead to an ideal window of time in which to deliver patient education. A short-term memory test was administered before and after (immediately after exercise, after 15 minutes, and after 30 minutes) a

*Corresponding author: Mark Deaton, Ph.D., CSCS, EIM, Assistant Professor of Exercise Science, Department of Health, Wellness and Human Performance, Morehead State University, USA, E-mail: m.deaton@moreheadstate.edu

Received November 26, 2012; Accepted November 27, 2012; Published November 28, 2012

Citation: Deaton M (2013) The Impact of Exercise on Short-term Memory Fading of Cardiac Rehabilitation Patients in Rural Eastern Kentucky. J Health Med Inform ૫: 119. doi:10.4172/2157-7420.1000119

Copyright: ( 2013 Deaton M. This is an open-access article distributed under the terms of the Creative Commons Attribution License, which permits unrestricted use, distribution, and reproduction in any medium, provided the original author and source are credited. 
60-minute exercise session, three times in one week. Information is received by sensory input (auditory, visual, etc.) and immediately processed [12]. Short-term processing can lead to immediate reactions or responses to a short-term memory test. If acute information is rehearsed by the person, information will be transferred from temporary to permanent storage. Long-term memory consolidation begins.

Patient educators, including physicians, nurses, and other allied health professionals, advise and teach on a daily basis [13]. A physician consultation is usually the beginning of a patient's education. In many of America's metropolitan hospitals and in some outpatient settings, patients are taught educational material through the use of computerized interfaces, and/or computer touch-screen technology [14]. The use of computer technology offers a library of interactive multimedia tutorials, webcasts, and illustrated handouts that expand upon verbal teaching methods.

A patient's clinical teaching usually starts in the hospital and could continue for years of follow-up visits (AACVPR, 2004). Patient education is dependent upon a specific diagnosis and correlating details of the chronic condition, and determines the specific educational strategy. A question currently being debated concerns the most efficient time (teachable moment) to deliver patient educational information in a clinical setting, is currently being debated [15].

Cognitive impairment may be present with many cardiac patients, receiving information vital to their recovery, therefore; a dilemma is born. This study is limited to the impact of exercise on the acute fading effect of cardiac patients' short-term memory. Acute fading effects can be described as loss of information, within 20 seconds of introduction. According to Brown [16] and Peterson and Peterson [17], only $10 \%$ of short-term memory is retained and transferred to long-term memory, leaving a large amount lost. Current research has revealed a link between exercise and positive brain adaptations $[4,10,11,18]$.

\section{Methods}

In this quantitative study, a repeated measure, quasi-experimental design was used to measure the impact of exercise on the fading effect of short-term memory [19]. A time-and-day interaction was analyzed to address the fading effect between trials and over days. Participants included 28 male and 12 female (40 total) active cardiac rehabilitation patients, between the ages of 39 and 81 , average age was 63.8 , in this short-term memory study. Randomness of participants is based more on convenience; therefore, various alternative explanations cannot be ruled out. All data were used in a quantitative (explanatory) form, for analysis and reporting.

Formative data were collected using a pretest short-term memory test, which provided initial data. The post test provided shortterm memory conditions, after the 60-minute exercise session was completed. Another short-term memory test, summative data, was repeated at 15 and 30 minutes after exercise, to determine the time interval of the fading effect. The participants were tested a total of 3 days in one week, before and after exercise sessions. Then, the data was analyzed and reported. The participants exercised 3 days per week, in accordance with the exercise physiologist's exercise prescription for frequency. Overall, a better understanding of the relationship of exercise and short-term memory within cardiac rehabilitation patients resulted from this design.

\section{Research Questions (RQ)}

RQ1. Is there a difference between pre short-term memory mean scores and summative post test mean scores, after 60 minutes of aerobic exercise in a cardiac rehabilitation facility? trial?

RQ2. Is there a difference between the second trial and the third

\section{RQ3. Is there a difference between the third and the fourth trial?}

RQ4. Does a fading effect exist over all 3 days of testing short-term memory in cardiac patients?

\section{Setting and Sample}

Participants were selected from a rural cardiac rehabilitation program in an eastern Kentucky hospital. The service area's population size is nearly 9,000 and faces numerous socioeconomic barriers. The location remains vague to protect participants' rights. The sample size will be 40 cardiac rehabilitation patients, due to the limited patient number to choose from. The rehabilitation facility is small, and only offers a limited number of patients to agree to participate. An alpha level of .05 was used for all statistical tests. The confidence level was set at $0.95(95 \%)$ to estimate the population proportion. This means that different samples from this population, with same input parameters, would consist of the population proportion value. Given the confidence level, sample size, and power, the sensitivity ranges from the critical $F$ of 1.81 and the effect size $F$ of 0.10 .

Each participant had experienced a major heart event in the past year, and was referred by one of three cardiologists in the area. A major heart event includes one of the following: myocardial infarction, coronary artery bypass grafting, heart valve replace/repair, heart transplant, stint placement, coronary angioplasty, or coronary heart disease. This criterion was used in selecting those patients eligible for the study. Each participant must match one or more of these diagnoses and consent to participation in the study.

\section{Instrumentation and Materials}

The primary instrument used in this study was a short-term memory test [20], consisting of six trials of random letters. Each line presents a group of letters for 3 seconds, followed by 10 seconds of verbal response time. The theoretical Brown-Peterson paradigm $[16,17]$ is a quasi-experimental procedure, where participants are shown letters, words, or numbers for a short period of time, and then asked to recall them after they are removed from sight. Multiple versions of this test have been used to determine information, such as how many digits should be in a phone number or a password, for example. Seven was tested as the most reliable and best fit for memorization, hence a phone number minus the area code. The Brown-Peterson paradigm was tested by Miller [21], Keppel and Underwood [22], Conrad [23], Baddeley [24]; and Atkinson and Shiffrin [25]. These multiple parallel tests indicate sufficient reliability. The memory tests of Brown [16], Peterson and Peterson [17], and Miller [21], sample different cognitive functions over a battery of tests, and generally have $90-100 \%$ specificity for working memory. Internal consistency of letter tests $(r=.76)$ is about 0.90 , with a repeated measures reliability of 0.70 to 0.80 [26].

\section{Omnibus Results}

A repeated-measures ANOVA was conducted to analyze the overall data collection of four short-term memory trials, executed over three days. The following is a definition of each variable: trial (time) 1 is the 
Citation: Deaton M (2013) The Impact of Exercise on Short-term Memory Fading of Cardiac Rehabilitation Patients in Rural Eastern Kentucky. J Health Med Inform I: 119. doi:10.4172/2157-7420.1000119

Page 3 of 5

pretest, trial (time) 2 is the first post test, trail (time) 3 is the post test given 15 minutes after exercise, and trial (time) 4 is the last post test. The interaction of time and day was used to best analyze effects and report results. Spherecity assumption was not met, therefore, the time effect is reported using Wilks' Lambda results from the multivariate tests. Wilks's $\Lambda=.19, F(3,38)=55.52, p<.001$, multivariate $\eta^{2}=.81$. The day effect results are Wilks's $\Lambda=.88, F(2,39)=2.71, p=.08$, multivariate $\eta^{2}=.12$. The results of the ANOVA are presented in table 1 .

Testing allowed for an analysis of fading effect between trials. Table 1 provides the ANOVA results for the time, day, and time-day effects. The Wilks' Lambda was chosen to report results. The descriptive statistics for each day's short-term memory scores are presented in table 2. Mauchly's test of sphericity for short-term memory scores are presented in table 3 . The within-subjects effects (time-day) interactions is presented with the fact that the assumption of sphericity had not been meet, as seen in table 3 .

\section{Findings for Research Question (RQ) 1}

The first research question asked if there is a difference between pre short-term memory mean scores and summative post test mean scores, after 60 minutes of exercise in a cardiac rehabilitation facility. The total number of correct responses (short-term memory test scores) from each short-term memory test was recorded on each participant, 3 days in 1 week. The question was answered by conducting repeated-

\begin{tabular}{|c|c|c|c|c|c|}
\hline \multicolumn{2}{|l|}{ Effect } & \multirow{2}{*}{\begin{tabular}{|l} 
Value \\
.30 \\
\end{tabular}} & \multirow{2}{*}{$\begin{array}{l}\mathbf{F} \\
2.51 \\
\end{array}$} & \multirow{2}{*}{$\begin{array}{l}\text { Sig. } \\
.04\end{array}$} & \multirow{2}{*}{\begin{tabular}{|l|}
$\begin{array}{l}\text { Partial Eta } \\
\text { Squared }\end{array}$ \\
.30 \\
\end{tabular}} \\
\hline Time*Day & Pillai's trace & & & & \\
\hline & Wilks' lambda & .70 & 2.51 & .04 & .30 \\
\hline & Hotelling's trace & .43 & 2.51 & .04 & .30 \\
\hline & Roy's Largest root & .43 & 2.51 & .04 & .30 \\
\hline \multirow[t]{4}{*}{ Time } & Pillai's trace & .81 & 55.52 & .00 & .81 \\
\hline & Wilks' lambda & .19 & 55.52 & .00 & .81 \\
\hline & Hotelling's trace & 4.38 & 55.52 & .00 & .81 \\
\hline & Roy's Largest root & 4.38 & 55.52 & .00 & .81 \\
\hline \multirow[t]{4}{*}{ Day } & Pillai's trace & .12 & 2.71 & .08 & .12 \\
\hline & Wilks' lambda & .88 & 2.71 & .08 & .12 \\
\hline & Hotelling's trace & .14 & 2.71 & .08 & .12 \\
\hline & Roy's Largest root & .14 & 2.71 & .08 & .12 \\
\hline
\end{tabular}

Table 1: ANOVA results for multivariate tests.

\begin{tabular}{|l|l|l|l|l|}
\hline & & & $\begin{array}{l}\text { 95\% confidence } \\
\text { interval }\end{array}$ & \\
\hline & M & SD & Lower Bound & Upper Bound \\
\hline Pre (day1) & 24.53 & 6.58 & 22.45 & 26.60 \\
\hline Pre (day2) & 24.45 & 6.17 & 22.50 & 26.40 \\
\hline Pre (day3) & 24.30 & 6.75 & 22.17 & 26.43 \\
\hline Post 1 (day 1) & 28.55 & 6.88 & 26.38 & 30.72 \\
\hline Post 1 (day 2) & 27.00 & 6.16 & 25.05 & 28.95 \\
\hline Post 1 (day 3) & 26.33 & 6.60 & 24.24 & 28.41 \\
\hline Post 2 (day 1) & 28.30 & 6.40 & 26.28 & 30.32 \\
\hline Post 2 (day 2) & 27.67 & 6.54 & 25.61 & 29.74 \\
\hline Post 2 (day 3) & 26.23 & 6.54 & 24.16 & 28.29 \\
\hline Post 3(day 1) & 26.33 & 6.41 & 24.30 & 28.35 \\
\hline Post 3(day 2) & 25.83 & 6.12 & 23.89 & 27.76 \\
\hline Post 3 (day 3) & 24.62 & 6.31 & 22.63 & 26.62 \\
\hline
\end{tabular}

Note. $\mathrm{N}=41$.

Table 2: Means, Standard Deviations and Confidence Intervals for short-term memory scores.

\begin{tabular}{|l|l|l|l|l|l|}
\hline $\begin{array}{l}\text { Within Sub- } \\
\text { jects Effect }\end{array}$ & Mauchly's W & Sig. & $\begin{array}{l}\text { Greenhouse- } \\
\text { Geisser }\end{array}$ & $\begin{array}{l}\text { Huynh- } \\
\text { Feldt }\end{array}$ & Lower-bound \\
\hline Time & .60 & .001 & .77 & .82 & .33 \\
\hline Day & .65 & .000 & .74 & .76 & .50 \\
\hline Time*Day & .37 & .009 & .76 & .87 & .17 \\
\hline
\end{tabular}

Note. ${ }^{*}$ Significant at the .05 level.

Table 3: Mauchly's test of sphericity.

\begin{tabular}{|l|l|l|l|l|}
\hline & Pre & Post (0 min) & Post (15 min) & Post (30 min) \\
\hline Day 1 & 24.52 & 28.55 & 28.30 & 26.32 \\
\hline Day 2 & 24.45 & 27.00 & 27.67 & 25.82 \\
\hline Day 3 & 24.30 & 26.32 & 26.22 & 24.62 \\
\hline
\end{tabular}

Table 4: Study matrix illustrating the means of short-term memory each day.

\begin{tabular}{|l|l|l|l|l|l|l|}
\hline Source & Time/Day & df & $\begin{array}{l}\text { Mean } \\
\text { Square }\end{array}$ & F & Sig. & $\begin{array}{l}\text { Partial Eta } \\
\text { Squared }\end{array}$ \\
\hline Time & Trial 1 vs. Later & 1 & 671.26 & 95.81 & $.000^{*}$ & .71 \\
\hline & Trial 2 vs. 3 & 1 & 1.44 & .57 & .46 & .01 \\
\hline & Trail 3 vs. 4 & 1 & 402.22 & 78.64 & $.000^{*}$ & .66 \\
\hline Day & Linear & 1 & 49.65 & 4.92 & $.03^{*}$ & .11 \\
\hline
\end{tabular}

Table 5: Results of the tests of within-subjects contrasts

measures ANOVA and analyzing the planned contrasts of withinsubjects.

The results for the tests of within-subjects contrasts indicated a significant difference between pre and post test means, $F(1,671)=95.81$, $p<.001, \eta^{2}=.71$. The results of planned contrasts, specific to research question one, is presented in table 4. Figures 1-3 also present a graphical display of the results.

Because the first research question is specific to the relationship between the pre short-term memory test (Trial 1) and the post shortterm memory (Trial 2, Trial 3, and Trial 4) tests, given after the participant completed 60 minutes of exercise, tests of within-subjects analysis were needed. Tests of within-subjects effects indicated statistical significance for the Greenhouse-Geisser and Huynh-Feldt for time and day differences, and sphericity was not assumed. The test for lower-bound was not statistically significant. The within-subjects effects results are presented in table 4 . The mean difference is significant at the .05 level.

Table 5 provides the results of the planned contrasts. Row 2, the time effect of trial 2 versus trial three, indicated no significant difference. This evidence means short-term memory scores remain elevated, from immediately post exercise, until 15 minutes later. Row 3, trial 3 versus trial four, indicated a significant difference. Once again this was a time effect, suggesting that means scores were different, and actually decreased between 15 minutes post to 30 minutes post exercise. These differences were significant at the .05 level, which means that each day of testing presented mean scores different from the previous day. These findings are illustrated in figure 1.

In summary of RQ 1 , the analysis demonstrates changes in post test memory scores, compared to the initial pre test scores on all 3 days. This change is best illustrated in figure 1 and 3 . The first research question examined the difference between the pre test mean scores and the mean of trials 2, 3, and 4. Improved short-term memory scores were observed immediately after 60 minutes of exercise. As shown in table 2, mean post scores were higher than mean pre test scores, immediately after 60 minutes of exercise. The initial increase in short-term memory scores occurred instantly after exercise. 
Citation: Deaton M (2013) The Impact of Exercise on Short-term Memory Fading of Cardiac Rehabilitation Patients in Rural Eastern Kentucky. J Health Med Inform 4: 119. doi:10.4172/2157-7420.1000119

Page 4 of 5

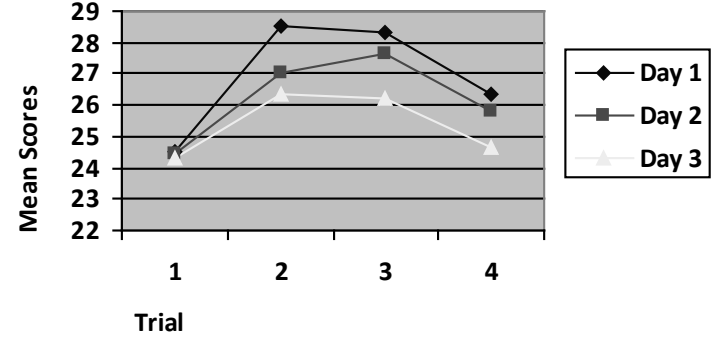

Figure 1: Estimated marginal means of short-term memory scores for 3 days.

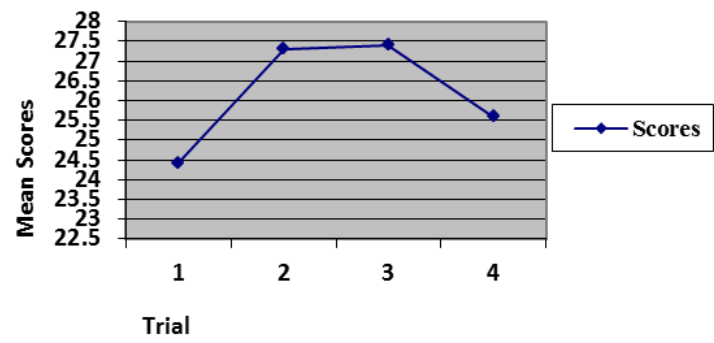

Figure 2: Estimated marginal means of short-term memory scores for each trial.

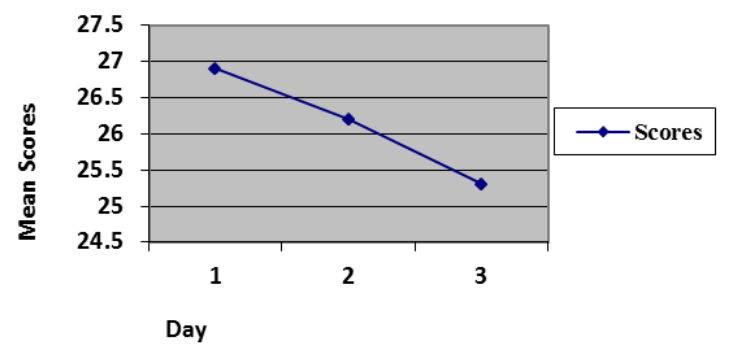

Figure 3: Estimated marginal means short-term memory scores for each day.

\section{Findings for Research Question (RQ) 2}

RQ 2 addressed a possible difference between the second trial (post test given immediately after 60 minutes of exercise), and the third trial given 15 minutes later. The results indicated no statistically significant difference between the second and third trial, $\mathrm{F}(1,1.44)=.568, p=.46, \eta^{2}$ $=.01$. Table 5 , second row indicates the findings.

\section{Findings for Research Question (RQ) 3}

Research question 3 addressed a possible difference between the third trial (posttest 15 minutes after exercise) and fourth trial (posttest 30 minutes after exercise). The results indicated a statistical significance between trial 3 and $4, F(1,402)=78.64, p<.001, \eta 2=.66$. The results are presented in table 5 , row 3 . From these results, a difference does exist between the third and fourth trial (see figures 1-3). Short-term memory scores begin to decline after 15 minutes post exercise (see figure 1).

\section{Findings for Research Question (RQ) 4}

The fourth research question addressed a possible three-day fading effect of short-term memory in cardiac patients. Figure 1 presents a graphical representation of the means of each trial, across three days. Figure 3 presents the estimated marginal means, for scores for each of the three days.
The results for the planned contrasts indicated a significant time effect on short-term memory scores, $\mathrm{F}(1,50)=4.92, p=.03, \eta^{2}=.11$. Table 5, fourth row presents the results that best answer this research question. From the results, a fading effect was evident over the three days of testing short-term memory. The mean short-term memory score results for each day are presented in table 6 .

The initial increase in short-term memory scores occurred immediately after exercise, and was sustained for at least 15 minutes. Tapering or trace decay was present at 30 minutes post exercise. This decay supports research question one and two. It should be noted that there was little change in means from post test, immediately after exercise to post test 15 minutes later; therefore, the significant trend was due to changes between pre test scores and scores after exercise.

\section{Discussion}

The purpose of this study was to determine the impact of exercise on the acute fading effect of short-term memory for cardiac patients. The results of this study have elucidated a possible window of delivery for cardiac patient educational material. Practitioners working with cardiac patients can utilize this information to adjust current practice of patient education and incorporate exercise, prior to the delivery of educational information. With a delay in the fading of acute information, a cardiac patient may understand a higher percentage of what is taught, if presented within 15 minutes after an exercise session. Higher short-term memory scores were observed immediately after exercise, and were sustained for up to 15 minutes. At 30 minutes, average scores started to decline in the direction of pretest score averages.

Data analysis from the study produced a pattern of data consistent throughout the duration. Trial-to-trial mean scores created a similar pattern from day 1 to day 2 to day 3 . This pattern is illustrated in figure 2. An increase in memory scores was indicated after exercise, remained elevated for 15 minutes, and then began to decline. The day-to-day interaction presented results of scores decreasing with each day, yet maintaining a similar pattern from day to day. Even though score patterns were similar for each day, the mean scores were lower as time progressed. The pattern of scores was lower for the second day, and then even lower for the third day. Future research may address this issue and develop a longer duration or measure other possible influences.

\section{Implications for Social Change}

In reflecting on the data analysis from this study and the patient outcomes, the implications are relevant for practitioner working in the field, to impact cardiac patients. Practical contributions of the study lead to a knowledge that cardiac rehabilitation patients experience an improved short-term memory after 60 minutes of exercise that also

\begin{tabular}{|l|l|l|l|l|l|l|}
\hline Source & Sum of Squares & df & F & Sig. & $\begin{array}{l}\text { Partial Eta } \\
\text { Squared }\end{array}$ & \\
\hline Time*Day & Greenhouse-Geisser & 63.81 & 4.55 & 3.73 & .004 & .09 \\
\hline & Huynh-Feldt & 63.81 & 5.21 & 3.73 & .003 & .09 \\
\hline & Lower-bound & 63.81 & 1.00 & 3.73 & .061 & .09 \\
\hline Time & Greenhouse-Geisser & 756.49 & 2.31 & 82.03 & $.000^{*}$ & .67 \\
\hline & Huynh-Feldt & 756.49 & 2.45 & 82.03 & $.000^{*}$ & .67 \\
\hline \multirow{2}{*}{ Day } & Lower-bound & 756.49 & 1.00 & 82.03 & $.000^{*}$ & .67 \\
\hline & Greenhouse-Geisser & 199.50 & 1.48 & 3.57 & $.047^{*}$ & .08 \\
\hline & Huynh-Feldt & 199.50 & 1.53 & 3.57 & $.046^{*}$ & .08 \\
\hline & Lower-bound & 199.50 & 1.00 & 3.57 & .066 & .08 \\
\hline
\end{tabular}

Table 6: Result of the tests of within-subjects effects. 
Citation: Deaton M (2013) The Impact of Exercise on Short-term Memory Fading of Cardiac Rehabilitation Patients in Rural Eastern Kentucky. J Health Med Inform 4: 119. doi:10.4172/2157-7420.1000119

Page 5 of 5

has a delayed fading effect. A possible window of opportunity that is most effective for the delivery of educational materials and concepts to cardiac patients, may exist post exercise. The most efficient time to provide new information may be immediately after the exercise is concluded. The cardiac patient becomes the most significant beneficiary from this study. For example, if a dietician or prescription medicine consult followed the exercise session, more information may be retained or understood, as opposed to the consult taking place prior to exercise.

The relationship between exercise and cognitive function can challenge previous contemporary theory, by adding exercise as a positive factor that decreases the fading effect of short-term memory functions. The study represented an important contribution to current practice for practitioners working with cardiac patients, researchers studying the topic of exercise and memory, and the benefit may be evident with individual cardiac patients that find they can remember the medical information provided after an exercise session. Health educators may be encouraged to assess post surgical memory capacity, and incorporate exercise prescriptions upon discharge, rehabilitation, or home care teaching.

There are several other possible conclusion and factors that must be considered in the conclusions of this study. Some other factors include improved blood flow effects, patient efforts, emotional status of the participant each day, and many more. The contribution of this study is targeted toward the clinical practice of patient educational delivery to encourage exercise, prior to the counseling or teaching of cardiac patients. The benefits of exercise, for a cardiac patient, incorporate both physiological and cognitive functioning.

\section{References}

1. Browne SM, Halligan PW, Wade DT, Taggart DP (2003) Postoperative hypoxia is a contributory factor to cognitive impairment after cardiac surgery. $\mathrm{J}$ Thorac Cardiovasc Surg 126: 1061-1064

2. Mello PB, Benetti F, Cammarota M, Izquierdo I (2009) Physical exercise can reverse the deficit in fear memory induced by maternal deprivation. Neurobiol Learn Mem 92: 364-369.

3. Pontifex MB, Hillman CH, Fernhall B, Thompson KM, Valentini TA (2009) The effect of acute aerobic and resistance exercise on working memory. Med Sci Sports Exerc 41: 927-934.

4. Ratey JJ, Hagerman E (2008) Spark: The revolutionary new science of exercise and the brain. Little Brown and Company, New York NY, USA.

5. Tulving E (1985) How many memory systems are there? American Psychologist 40: $385-398$

6. Tulving E, Craik FIM (2000) The Oxford handbook of memory. Oxford, University Press, New York, USA

7. Audiffren M, Tomporowski PD, Zagrodnik J (2009) Acute aerobic exercise and information processing: Modulation of executive control in a random number generation task. Acta Psychol (Amst) 132: 85-95.

8. Garcia-Capdevila S, Portell-Cortes I, Torras-Garcia M, Coll-Andreu M, CostaMiserachs D (2009) Effects of long-term voluntary exercise on learning and memory processes: dependency of the task and level of exercise. Behav Brain Res 202: 162-170.

9. Masley S, Roetzheim R, Gualtieri T (2009) Aerobic exercise enhances cognitive flexibility. J Clin Psychol Med Settings 16: 186-193.

10. Stroth S, Hille K, Spitzer M, Reinhardt R (2009) Aerobic endurance exercise benefits memory and affect in young adults. Neuropsychol Rehabil 19: 223243

11. Summerford C (2001) What is the impact of exercise on brain function for academic learning. Teaching Elementary Physical Education 12: 6-8.
12. Slavin RE (2010) Educational psychology: theory into practice. (9 $9^{\text {th }}$ edition) Pearson Allyn \& Bacon Publishing.

13. Patient Education Institute (2008) Clinical education methods

14.(2004) Guidelines for cardiac rehabilitation and secondary prevention programs. ( $4^{\text {th }}$ edition), AACVPR 288.

15. Ille R, Lahousen T, Schweiger S, Hofmann P, Kapfhammer HP (2007) Influence of patient-related and surgery-related risk factors on cognitive performance, emotional state, and convalescence after cardiac surgery. Cardiovasc Revasc Med 8: 166-169.

16. Brown J (1958) Some tests of the decay theory of immediate memory. Quart Exp Psychol 10: 12-21.

17. Peterson LR, Peterson MJ (1959) Short-term retention of individual verbal items. J Exp Psychol 58: 193-198.

18. Tomporowski PD, Ellis NR (1986) Effects of exercise on cognitive processes: A reveiw. Psychological Bull 99: 338-346.

19. Leedy PD, Ormrod JE (2004) Practical Research; planning and design. ( $8^{\text {th }}$ ed) Prentice Hall, New Jersey, USA.

20. http://faculty.washington.edu/chudler/neurok.html

21. Miller GA (1956) The magical number seven, plus or minus two: some limits on our capacity for processing information. Psychol Rev 63: 81-97.

22. Keppel G, Underwood BJ (1962) Proactive inhibition in short-term retention of single items. J Verbal Learning Verbal Behav 1: 153-161.

23. Conrad R (1963) Acoustic confusions and memory span for words. Nature 197 1029-1030.

24. Baddeley AD (1966) Short-term memory for word sequences as a function of acoustic, sematic, and formal similarity. Q J Exp Psychol 18: 362-365.

25. Atkinson RC, Shiffrin RM (1968) Human memory: a proposed system and its control processes. Psychology of Learning and Motivation 2: 89-195.

26. Beckmann B, Holling H, Kuhn JT (2007) Reliability of verbal-numerical working memory tasks. Pers Individ Dif 43: 703-714. 